\title{
The Effect of Ph-cycling and Toothbrushing Simulations on Surface Roughness of Bulk-Fill Composites
}

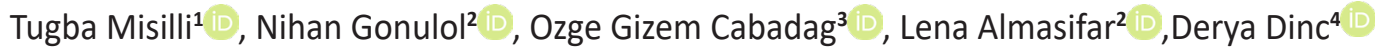 \\ ${ }^{1}$ Canakkale Onsekiz Mart University, Faculty of Dentistry, Department of Restorative Dentistry, Canakkale, Turkey \\ ${ }^{2}$ Ondokuz Mayis University, Faculty of Dentistry, Department of Restorative Dentistry, Samsun, Turkey \\ ${ }^{3}$ Pamukkale University, Faculty of Dentistry, Department of Restorative Dentistry, Denizli, Turkey \\ ${ }^{4}$ Konya Oral and Dental Health Hospital, Konya, Turkey \\ Correspondence Author: Ozge Gizem Cabadag \\ E-mail: gizemyndny@outlook.com \\ Received: $29.10 .2020 \quad$ Accepted: 17.07 .2021
}

\begin{abstract}
Objective: This study aimed to compare surface roughness values $(\mathrm{Ra})$ of different posterior composites after $\mathrm{pH}$-cycling and toothbrushing simulation.

Methods: Fifty disc-shaped specimens $(8 \times 2 \mathrm{~mm})$ were prepared by using three bulk-fill composites [Filtek Bulk Fill Posterior (FBF), SonicFill 2 (SF), X-tra fil (XF)], a flowable [G-aenial Universal Flo (GF)], and a microhybrid composite [Filtek Z250 (Z250)]. After initial roughness (Ra) measurements were performed with a contact profilometer, the samples were subjected to a pH-cycling model for 10 days and Ra ${ }_{1}$ values were recorded. Then, the samples were subjected to toothbrushing simulation for $4 \mathrm{~min}$ and final values $\left(\mathrm{Ra}_{2}\right)$ were recorded. From each group, a representative sample was analyzed with an optical profilometer. The values were analyzed by two-way ANOVA with repeated measures on one factor (period) followed by Tukey's test $(p<0.05)$.

Results: Significant differences were found among materials regardless of experimental periods. The lowest Ra values were determined in GF and Z250 groups. The highest value was obtained in SF, but this value was not statistically significant different from that obtained in XF group. Brushing procedure after chemical degradation led to an increase in surface roughness of all materials except FBF, which was not statistically significant.
\end{abstract}

Conclusion: While Ra values showed differences depending on the materials, $\mathrm{pH}$-cycling and toothbrushing simulation did not have a significant effect on these values.

Keywords: Bulk-fills, pH-cycling, resin-based composites, surface roughness, toothbrushing

\section{INTRODUCTION}

Improvements in both the aesthetic and mechanical properties of resin-based materials have resulted in the extensive use of direct composite resin restorations in anterior and posterior teeth (1). Bulk-fill composites represent one of the most remarkable developments in restorative dentistry in recent years. These materials have less polymerization shrinkage than conventional resin composites, as well as greater light transmission resulting from less scattering at the matrix-filler interface, and enhanced polymerization depth resulting from the material's greater translucency. Bulk-fill composites are also easier to manipulate, which helps to accelerate the restoration process in deep cavities $(2,3)$. Despite these advantages, surface roughness remains a problem inherent to the material, and researchers agree that with time direct restorations performed with bulk-fill composites undergo changes in surface roughness (4-8).

Flowable composites have reduced filler loading that typically results in a low viscosity, allowing them to flow easily, spread homogeneously and closely adapt to the cavity form to produce the desired tooth anatomy. However, the lower filler loading also results in inherently inferior mechanical properties, making flowable composites more susceptible to wear and other forms of attrition than conventional composites (9). G-aenial Universal Flo has been introduced as a highly filled injectable composite, which shows higher viscosity and improved mechanical properties, similar to conventional composites. Furthermore, unlike other flowable composites, G-aenial Universal Flo eliminates the need for an additional covering 
layer with a more wear-resistant regular resin composite in areas under occlusal force, thus facilitating the restoration process $(4,10,11)$. This unique composite blends the properties of two types of resin-based composites, flowable and conventional, and showed a smoother surface after wear test compared to other flowable and conventional composites tested (12). However, information regarding the surface roughness of this flowable resin composite is limited.

Oral environment conditions are known to threaten the integrity and longevity of resin-based materials. In particular, the chemical environment of the oral cavity has been shown to affect the surface properties of resinbased restorative materials $(13,14)$. Low environmental $\mathrm{pH}$ caused by cariogenic biofilm and acidic drinks, as well as water absorption and erosion can all result in material degradation $(1,15)$, and the degradation of the matrix, filler, and matrix-filler interface on the surface of restoration may further increase roughness and abrasion (16).

The effect of toothbrushing on the surface roughness of resin composites also need to be taken into consideration in assessing the clinical performance of these materials. When softened restorations due to chemical degradation are exposed to brushing abrasion as well as chewing forces, a gradual removal of material occurs (17). Moreover, brushing abrasion is the main cause of material loss, especially in non-stress-bearing areas. Such wear can result in increasing surface roughness, which can be responsible for bacterial colonization and stain accumulation (18). A previous study has indicated that the variations in $\mathrm{pH}$ altered the surface characteristics of the restorative materials (19) and these materials may be more prone to brushing abrasion at lower $\mathrm{pH}$ values (20).

In clinical situations, there is always a dynamic process between demineralization and remineralization in the oral cavity (21). Many previous studies have used a $\mathrm{pH}$-cycling regime that simulate in vitro the chemical degradation that occurs as a result of frequent sugar consumption (1820). This study evaluated the effect of brushing abrasion, in association with low $\mathrm{pH}$ on the surface roughness of three different high-viscosity bulk-fill composites as well as one conventional microhybrid and one flowable composite. The null hypothesis was that there would be no difference between the surface roughness of the tested composites subjected to simulated dynamic $\mathrm{pH}$-cycling prior to the toothbrushing test.

\section{METHODS}

\subsection{Specimen preparation}

The composition and manufacturer of the restorative materials used in the present study are listed in Table 1.
Table 1. The compositions and the manufacturer details of the tested composite resins

\begin{tabular}{|c|c|c|c|c|c|}
\hline Code & Material & Type & $\begin{array}{l}\text { Filler } \\
\text { content } \\
\text { (wt.\% / } \\
\text { vol.\%) }\end{array}$ & $\begin{array}{l}\text { Filler size } \\
(\mu \mathrm{m})\end{array}$ & $\begin{array}{l}\text { Manufacturer \& } \\
\text { Lot no. }\end{array}$ \\
\hline GF & $\begin{array}{l}\text { G-ænial } \\
\text { Universal } \\
\text { Flo }\end{array}$ & nanohybrid & $\begin{array}{l}\mathrm{SiO}_{2} \\
\text { strontium } \\
\text { glass } \\
69 / 50\end{array}$ & $0.01-0.2$ & $\begin{array}{l}\text { GC Corporation, } \\
\text { Tokyo, Japan } \\
1804053\end{array}$ \\
\hline $\mathrm{Z250}$ & $\begin{array}{l}\text { Filtek Z250 } \\
\text { Universal } \\
\text { Restorative }\end{array}$ & microhybrid & $\begin{array}{l}\text { zirconium/ } \\
\text { silica } \\
82 / 60\end{array}$ & $\begin{array}{l}0.01-3.5 \\
\text { avg. } 0.6 \mu \mathrm{m}\end{array}$ & $\begin{array}{l}\text { 3M ESPE, } \\
\text { St Paul, MN, } \\
\text { USA } \\
\text { N885546 }\end{array}$ \\
\hline FBF & \begin{tabular}{|l} 
Filtek \\
Bulk Fill \\
Posterior \\
Restorative
\end{tabular} & nanofilled & $\begin{array}{l}\text { silica, } \\
\text { zirconia, } \\
\text { YbF }_{3} \\
76.5 / 58.4 \\
\end{array}$ & $\begin{array}{l}0.02 \text { silica, } \\
0.004-0.011 \\
\text { zirconia } \\
0.1 \mathrm{YbF}_{3}\end{array}$ & $\begin{array}{l}\text { 3M ESPE, } \\
\text { St Paul, MN, } \\
\text { USA } \\
\text { N938940 }\end{array}$ \\
\hline$X F$ & X-tra fil & microhybrid & $\begin{array}{l}\text { Ba-B-Al-Si } \\
\text { glass } \\
86 / 70.1\end{array}$ & $0.05-10$ & \begin{tabular}{|l} 
VOCO, \\
Cuxhaven, \\
Germany \\
1447376 \\
\end{tabular} \\
\hline SF & SonicFill 2 & nanohybrid & $\begin{array}{l}\mathrm{ZrO}_{2^{\prime}} \mathrm{SiO}_{2} \\
82 / 68.5\end{array}$ & - & $\begin{array}{l}\text { Kerr, } \\
\text { Orange, CA, } \\
\text { USA } \\
6385712\end{array}$ \\
\hline
\end{tabular}

$\mathrm{SiO}_{2}$, Silicon dioxide; $\mathrm{YbF}_{3}$, Ytterbium trifluoride.

$\mathrm{ZrO}_{2}$ : Zirconium dioxide

A teflon mold was used to create 10 disc-shaped specimens $(8 \times 2 \mathrm{~mm})$ from 5 different resin composites for a total of 50 specimens. Specimen surfaces were covered with Mylar strips and a glass slide, and pressure was applied to extrude excess composite. Samples were polymerized with a LED light-curing unit at $1200 \mathrm{~mW} / \mathrm{cm}^{2}$ for $20 \mathrm{~s}$ (Elipar S10, 3M ESPE, St Paul, MN, USA), which was periodically monitored with a radiometer (LED radiometer, SDI, Australia). All samples were marked on the bottom surface with an identification number and stored individually in $1 \mathrm{ml}$ of distilled water at $37^{\circ} \mathrm{C}$. After $24 \mathrm{~h}$, the top surfaces of the specimens were ground under water cooling with abrasive silicon carbide paper (600 and 1000 grit). The polishing was performed with one-step diamond micro-polisher cups (PoGo, Dentsply, DeTrey, Konstanz, Germany) with light intermittent pressure for $15 \mathrm{~s}$ using a slow-speed handpiece rotating at a maximum of $12,000 \mathrm{rpm}$ to prevent heat and grooves build-up. Samples were cleaned ultrasonically for $10 \mathrm{~min}$ and stored in $100 \%$ humidity until $\mathrm{pH}$ cycling. All procedures were performed by a single operator.

\subsection{Surface roughness measurements}

The surface roughness of composite specimens was measured with a surface profilometer (Surfcorder SE 1700, Kosaka Corp, Tokyo, Japan) after polishing (baseline), pH-cycling and toothbrushing test. Measurements were obtained from the top surface of each specimen using a tip with a 2- $\mu$ m diameter, length of $1.25 \mathrm{~mm}$, a speed of $0.1 \mathrm{~mm} / \mathrm{s}$ and cutoff of 0.25 $\mathrm{mm}$. Three sequential measurements were taken from each specimen, and the average of the three measurements was 
recorded as the Ra value $(\mu \mathrm{m})$ for that specimen. "Ra," was used to define the baseline measurements.

\section{3. $p H$-cycling test}

First, samples were stored in $5 \mathrm{ml}$ of a pH 4.3 demineralization solution comprised of $2.0 \mathrm{mM}$ calcium and $2.0 \mathrm{mM}$ phosphate in a buffer solution of $74.0 \mathrm{mM}$ acetate. After $6 \mathrm{~h}$ storage at $37^{\circ} \mathrm{C}$, samples were then rinsed with distilled water and immersed for $18 \mathrm{~h}$ in a $\mathrm{pH} 7.0$ remineralization solution (5 $\mathrm{ml}$ ) comprised of $1.5 \mathrm{mM}$ calcium and $0.9 \mathrm{mM}$ phosphate and $150 \mathrm{mM}$ potassium chloride in a buffer solution of 20 $\mathrm{mM}$ Tris (hydroxymethyl-aminomethane) at $37^{\circ} \mathrm{C}$ (20). The $\mathrm{pH}$-cycling regime was repeated 10 times, with solutions changed daily. All specimens were therefore submitted to surface roughness measurements $\left(\mathrm{Ra}_{1}\right)$, as described above.

\subsection{Simulation of toothbrushing}

Following $\mathrm{pH}$-cycling, samples were subjected to mechanical brushing using a custom-built brushing device. Five electric rechargeable toothbrushes (Vitality Precision Clean, Oral-B Braun $\mathrm{GmbH}$ ) were screwed to the brushing apparatus (Figure 1). Sample discs were secured in silicon molds and placed under the brush heads to ensure contact between samples and toothbrush bristles. The toothbrushes were operated with a constant load of $200 \mathrm{~g}$, a typical load used in other brushing studies $(11,17,22-24)$, which was measured by a precision scale attached to the machine. Samples were brushed in circular movements for $4 \mathrm{~min}$, with $2 \mathrm{ml}$ of distilled water applied to each sample at 30-s intervals. This was determined to simulate approximately 6 months of brushing based on the mean brushing time per tooth surface corresponding to 2 seconds per day, as indicated in their study using electric brushes by Jasse et al. (25). Following brushing, samples were rinsed with deionized water and sonicated in deionized water for $10 \mathrm{~min}$. The final $\mathrm{Ra}_{2}$ values were measured as described previously.

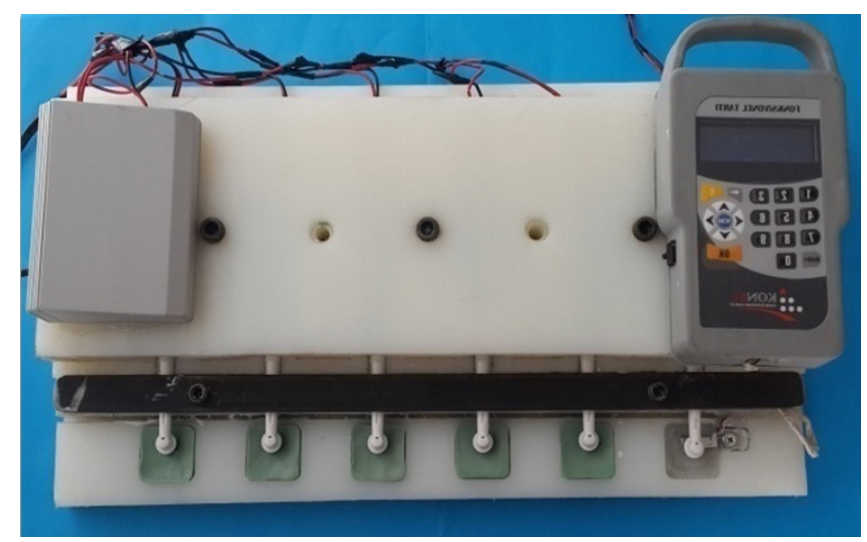

Figure 1. The custom-built brushing unit used in the study.

\subsection{Three-dimensional (3D) surface images}

3D profiling was performed on a randomly selected sample from each composite group with the help of the
3D non-contact optical-profilometer (Contour GT-K, Bruker, Tucson, AZ, USA) after polishing (baseline), $\mathrm{pH}$-cycling and toothbrushing test (Figure 2-6). Scanning was performed using an objective of $5 x$ (in order to include as much of the specimen area as possible in roughness calculations), a scanning zone of $150 \mu \mathrm{m}$ (height) $\times 3 \mathrm{~mm}$ (length), and a speed of $40 \mu \mathrm{m} / \mathrm{sec}$.

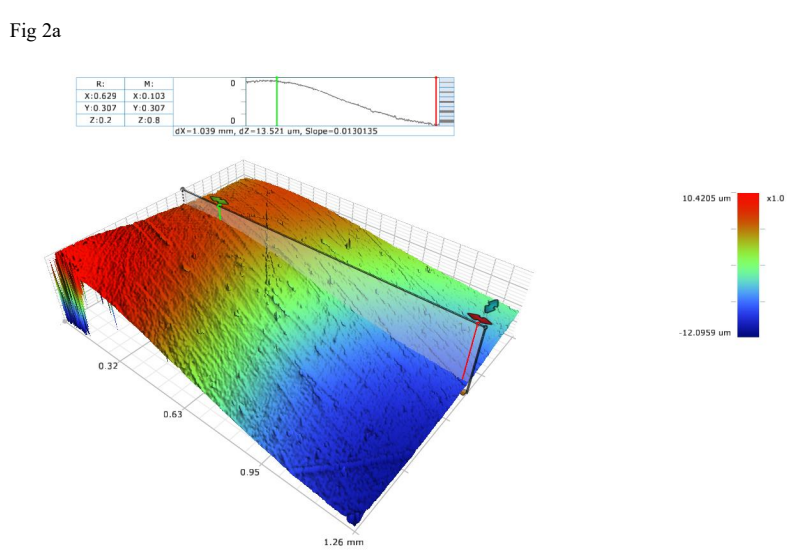

Fig $2 b$
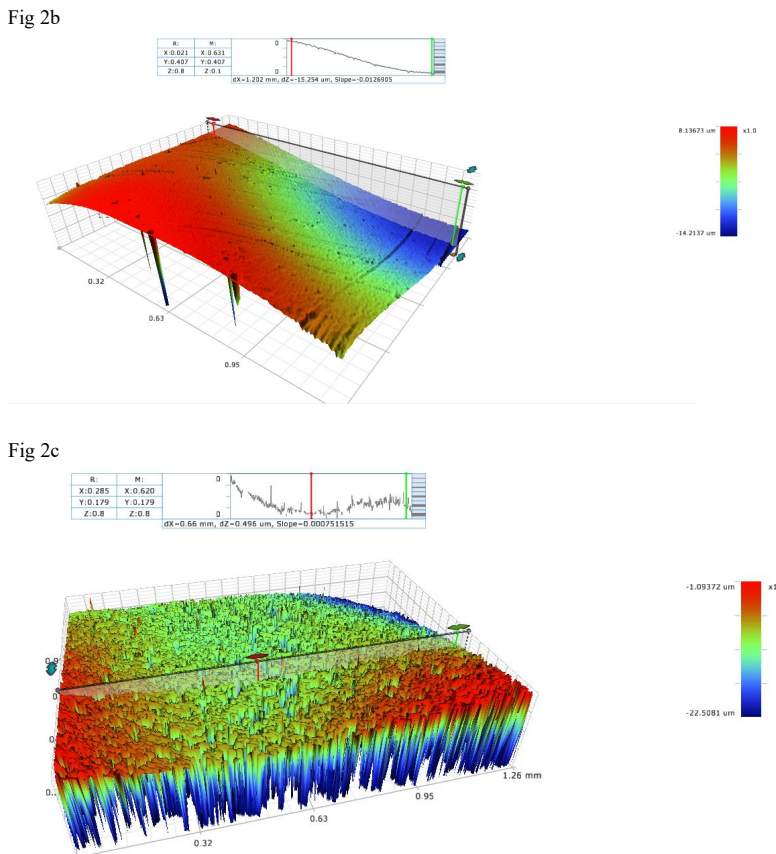

Figure 2. $3 D$ surface images of the specimen in group GF: (a) at baseline; (b) after $\mathrm{pH}$-cycling; (c) after toothbrushing.

\subsection{Statistical analysis}

The SPSS 19.0 statistical package program (SPSS Inc., Chicago, IL, USA) was used for the analyses. The recorded data was evaluated for normality of distribution and equality of variance. After this, a two-way ANOVA with repeated measures on one factor (experimental period) was used to analyze the differences in surface roughness values of composite groups. Multiple comparisons were performed using Tukey's HSD test. A level of 0.05 was considered statistically significant. 


\section{RESULTS}

Surface roughness values ( $\mathrm{Ra}$ ) for each material at all experimental periods (baseline, after $\mathrm{pH}$ cycling, and after simulated brushing) are given in Table 2 .

Table 2. Mean surface roughness values $(\mu \mathrm{m})$ and standard deviations ( $\pm s d)$ at baseline $\left(R a_{0}\right)$, after $\mathrm{pH}$-cycling regime $\left(R a_{1}\right)$ and after toothbrushing test $\left(\mathrm{Ra}_{2}\right)$

\begin{tabular}{|c|c|c|c|c|}
\hline Group & $\mathbf{R a}_{0}$ & $\mathrm{Ra}_{1}$ & $\mathrm{Ra}_{2}$ & Average \\
\hline GF & $0.06( \pm 0.03)$ & $0.07( \pm 0.02)$ & $0.1( \pm 0.04)$ & $0.08( \pm 0.03)^{\mathrm{C}}$ \\
\hline Z250 & $0.09( \pm 0.03)$ & $0.1( \pm 0.04)$ & $0.13( \pm 0.09)$ & $0.11( \pm 0.06)^{\mathrm{C}}$ \\
\hline FBF & $0.22( \pm 0.09)$ & $0.2( \pm 0.09)$ & $0.21( \pm 0.1)$ & $0.21( \pm 0.09)^{\mathrm{B}}$ \\
\hline XF & $0.25( \pm 0.05)$ & $0.32( \pm 0.13)$ & $0.36( \pm 0.19)$ & $0.31( \pm 0.14)^{\mathrm{A}}$ \\
\hline SF & $0.35( \pm 0.05)$ & $0.34( \pm 0.06)$ & $0.37( \pm 0.08)$ & $0.35( \pm 0.07)^{\mathrm{A}}$ \\
\hline
\end{tabular}

$n=10 ;(p<0.05)$

Different capital letters indicate statistically significant differences in the columns.

Fig 3a
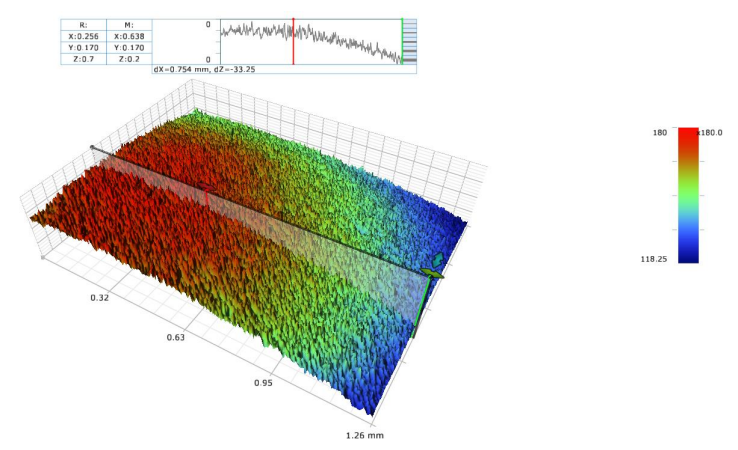

Fig $3 b$

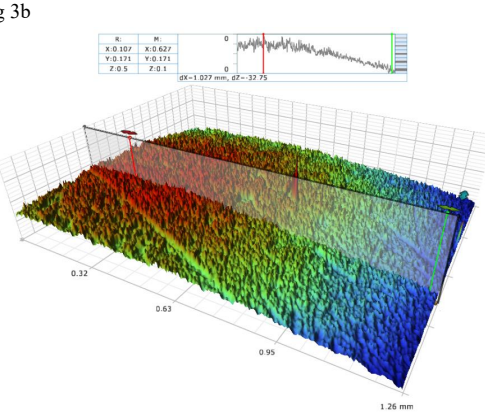

Fig 3c

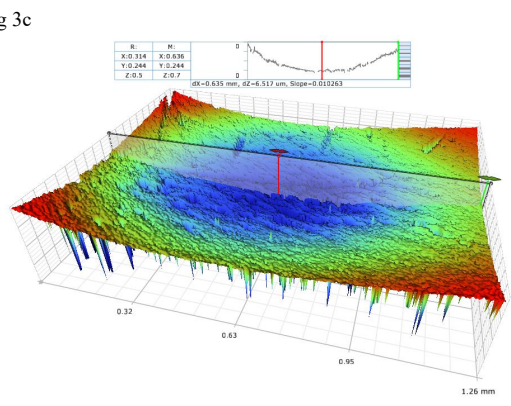

Figure 3. 3D surface images of the specimen in group Z250: (a) at baseline; (b) after $\mathrm{pH}$-cycling; (c) after toothbrushing.

The two-way ANOVA with repeated measures on one factor (period) revealed a significant effect of the main factor: "restorative materials" $(p<0.001)$. The other main factor, "experimental period" ( $\mathrm{p}=0.064)$ and the interaction between "restorative materials" * "experimental period" $(p=0.650)$ were not significant.

There were statistically significant differences among the restorative materials regardless of the experimental periods. Tukey's HSD test showed that there was no significant difference between group SF and XF $(p>0.05)$, but both materials had significantly higher surface roughness values than all other groups $(p<0.05)$. Although group FBF exhibited significantly lower surface roughness values than SF and XF groups, this value was significantly higher than $Z 250$ and GF groups $(p<0.05)$. There was no statistically significant difference between GF and Z250 groups with the lowest roughness values $(p>0.05)$.

Apart from the FBF group, the roughness values of all composites tested showed an increase following toothbrushing test $\left(\mathrm{Ra}_{2}\right)$ compared to their baseline values $\left(R a_{0}\right)$; however, none of these increases was statistically significant $(p>0.05)$.

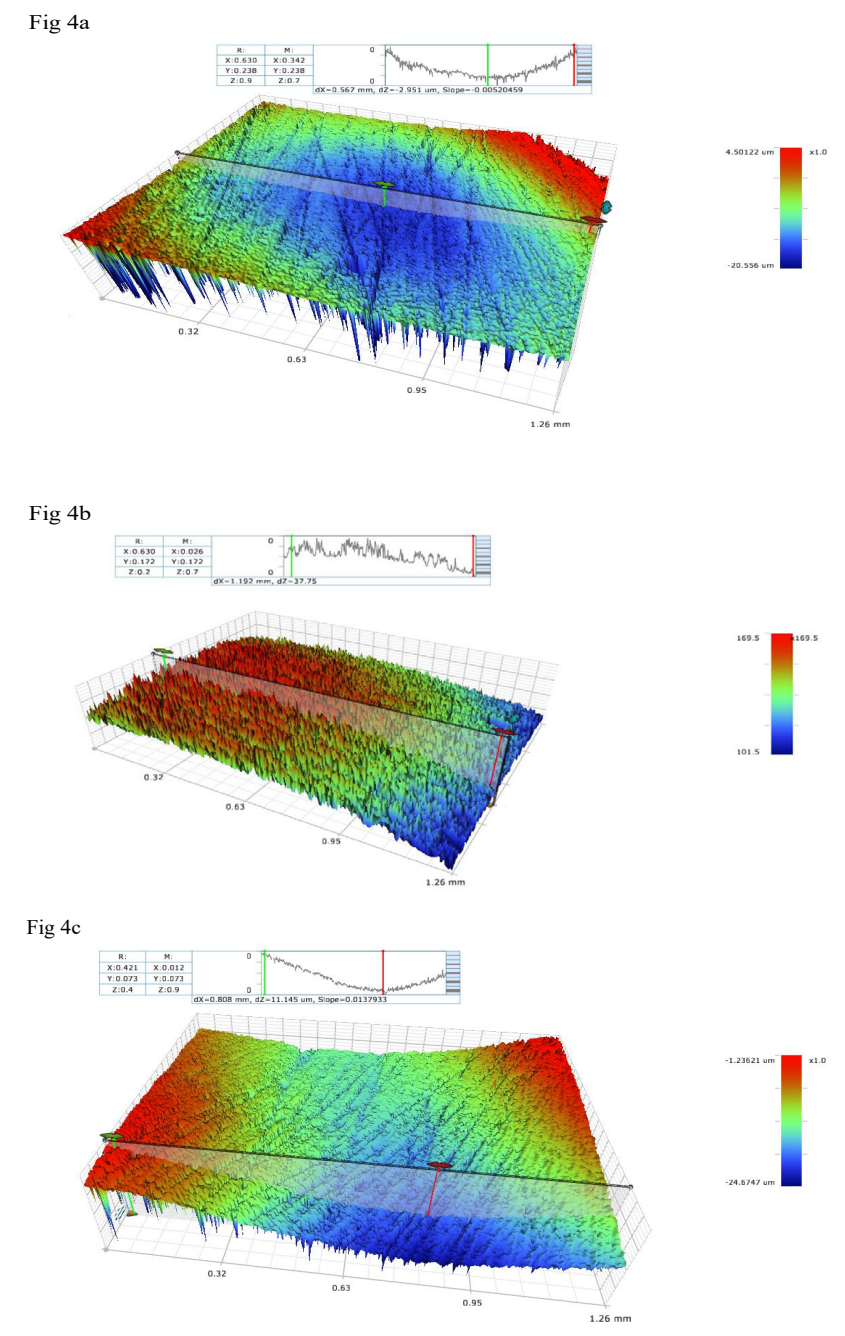

Figure 4. $3 D$ surface images of the specimen in group FBF: (a) at baseline; (b) after $\mathrm{pH}$-cycling; (c) after toothbrushing. 

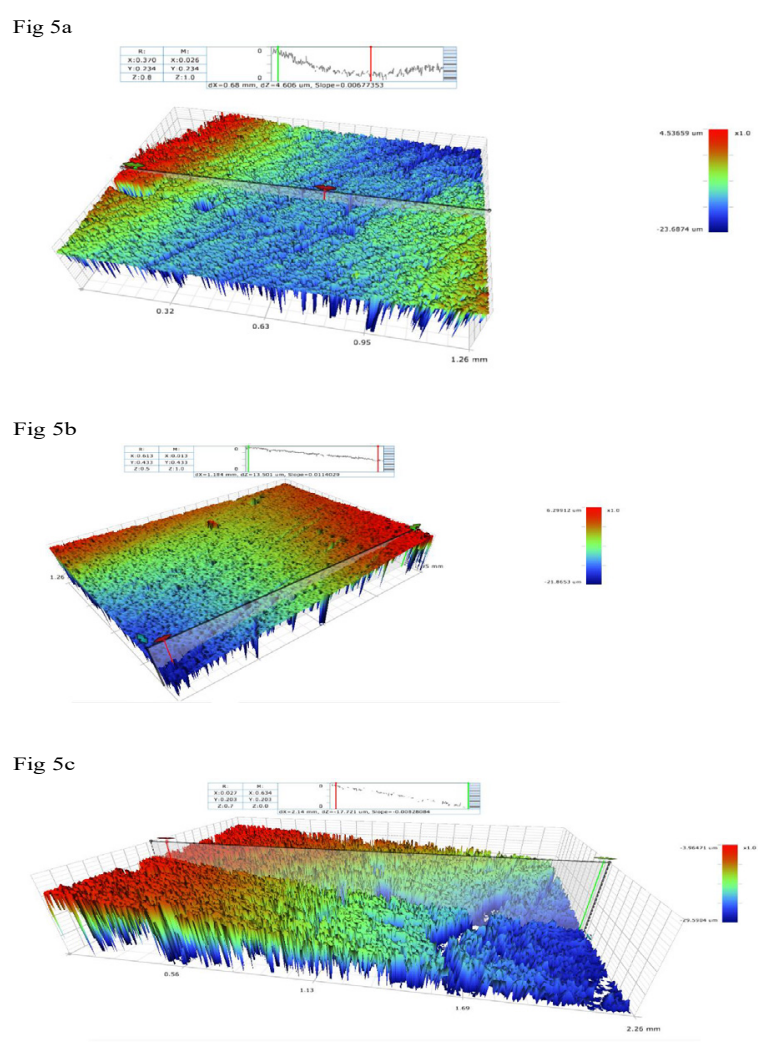

Figure 5. 3D surface images of the specimen in group XF: (a) at baseline; (b) after $\mathrm{pH}$-cycling; (c) after toothbrushing.
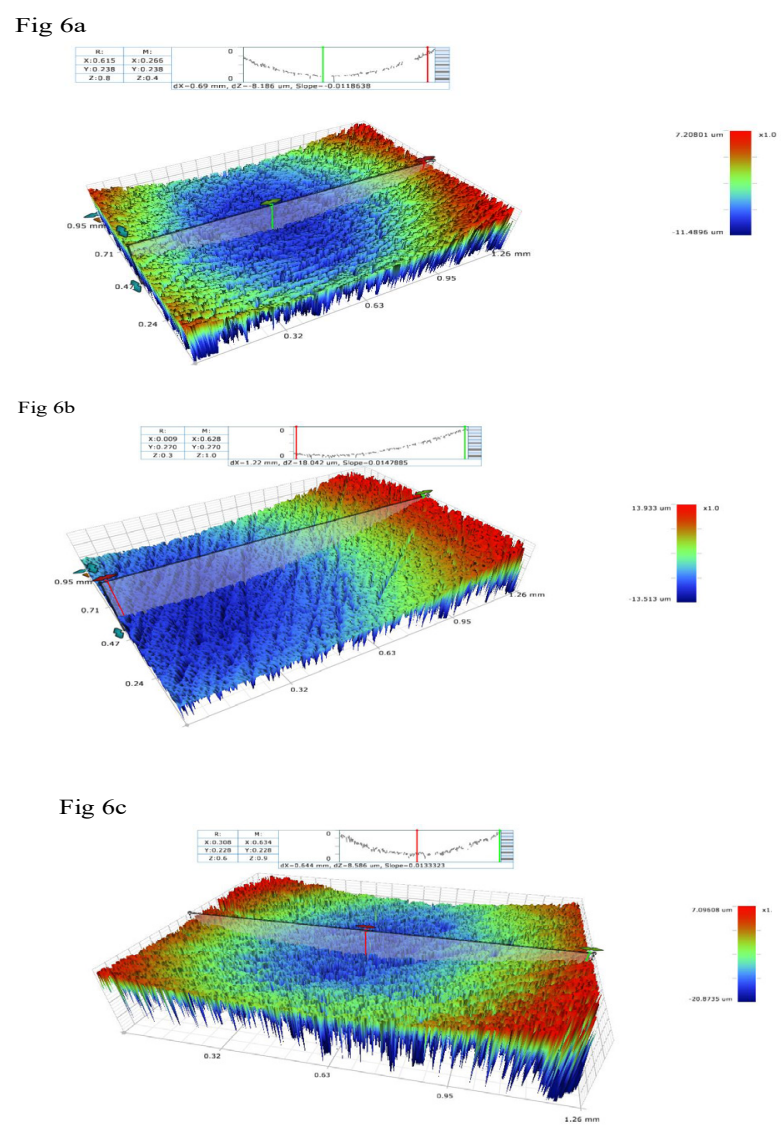

Figure 6. $3 D$ surface images of the specimen in group SF: (a) at baseline; (b) after $\mathrm{pH}$-cycling; (c) after toothbrushing.
Figure 2-6 shows the 3D optical images of the tested composite materials, at baseline, after $\mathrm{pH}$-cycling and after toothbrushing test. At baseline, images of all the materials displayed largely smooth surfaces with just a few small porosities from grinding. Images of all the tested composites after $\mathrm{pH}$-cycling were similar to the baseline images with the exception of group XF, which clearly exhibited surface damage. After toothbrushing simulation, while groups GF, Z250 and XF exhibited their roughest patterns (Figure 2c, $3 c, 5 c)$, other two composites (FBF, SF) did not show any significant change in their images (Figure 4c, 6c). Following toothbrushing test, the surface image of the XF specimen (Figure $5 \mathrm{c}$ ) appeared to be the roughest of all the specimens tested.

\section{DISCUSSION}

The null hypothesis was rejected because the surface roughness values and surface patterns showed variations among the tested composite materials, regardless of $\mathrm{pH}$ cycling and toothbrushing tests.

In the oral environment, composite materials may be intermittently or continuously exposed to chemicals present in saliva, food and beverages. While intermittent exposure occurs during eating or drinking and continues until teeth are cleaned, bacterial decomposition of adherent debris may result in continuous exposure (14). The disintegration of the resin composite structure is mainly caused by hydrolytic degradation accelerated by low $\mathrm{pH}$, thereby adversely affecting the abrasion resistance of the materials (26). The in vivo behavior of acid-exposed restorative materials can be assessed in vitro through the dynamic process of $\mathrm{pH}$ cycling. First proposed in 1986 by Featherstone et al. (27), the procedure involves demineralization/remineralization cycles simulated by immersing enamel samples in acidic and supersaturated buffer solutions, respectively. A 2007 study by Silva et al. (19) confirmed that the surface properties of restorative materials were influenced by $\mathrm{pH}$ variations in $\mathrm{pH}-$ cycling. Therefore, this study used dynamic $\mathrm{pH}$-cycling with a $\mathrm{pH} 4.3$ demineralization solution ( $10 \mathrm{~d}$ ) to simulate severe acid exposure.

In order to simulate in vitro mechanical degradation caused by oral-hygiene procedures, this study used a custom-built toothbrushing device. Mechanical brushing is a convenient way to simulate regular oral hygiene procedures that provides standardization of the amount, distance, and frequency of force applied to specimens by brushing $(28,29)$. The present study simulated approximately 6 months of brushing based on the mean brushing time which corresponds to $2 \mathrm{~s}$ per day per tooth surface (25). Moreover, considering that in clinical situations, brushing may be performed following exposure to a chemical agent, this study subjected specimens to toothbrushing test following $\mathrm{pH}$-cycling simulation. In this way, it was also aimed to evaluate their longevity in the oral environment instead of comparing only the performances of different materials. 
Mechanical profilometry, which is the most common method used to assess the surface roughness of composite materials, is an easily applied, widely available and relatively inexpensive procedure, but it is restricted by the spatial dimension of the stylus, force of measurement, rate of sampling and z-axis calibration (30). In this study, a non-contact optical profilometer in addition to mechanical profilometer was used to better record the characteristic 3-D nature of resin composite surface topography $(31,32)$.

This study investigated the surface roughness of 3 different high-viscosity bulk-fill composites (FBF, SF and XF) by comparing with conventional microhybrid and flowable resin composites. In the initial roughness measurements, different polishing results were obtained according to the type of resin composite employed despite the same polishing process. While a surface roughness value of $0.28 \mu \mathrm{m}$ has been reported to be detectable by the human tongue (33), a value of 0.2 $\mu \mathrm{m}$ is considered the critical threshold for bacterial retention (34). In the present study, only GF and Z250 had values below this critical threshold at baseline and in both experimental periods. The final surface quality of resin composites after polishing has been shown to be affected by the size, shape, hardness and amount of filler particles $(35,36)$ In common, a positive correlation is expected between filler size and surface roughness. This pattern is consistent with the results of this study, as the SF and XF, which have a heterogeneous distribution in filler size with large particles (>20 $\mu \mathrm{m})$ (3), presented the roughest surfaces. This finding may also result from the possibility that the glass particles used as inorganic fillers being harder than the abrasive particles in the polishing system. As indicated by Ergücü and Türkün (35), when the filler particles are harder, the organic matrix is first worn away, filler particles remain protrusive on the surface, and then the roughness increases. In this study, the cups in the Pogo polishing system may be unable to flatten the glass filler particles, thereby resulting in rough surfaces (36). Barkmeier et al. (37) have also noted that for SonicFill, Scanning Electron Micrographs after the process of wear simulation showed a surface containing fractured large glass filler particles and voids resulting from plucking out of these particles.

The XF was the only composite group that showed a relatively high increase in roughness values after $\mathrm{pH}$-cycling. Furthermore, its surface texture was significantly affected by both $\mathrm{pH}$-cycling (Figure $5 \mathrm{~b}$ ) and simulated toothbrushing (Figure 5c). Likewise, another surface roughness study demonstrated that X-tra fil had the worst performance at baseline, during and after aging simulation (4). Contrary to this result, in situ study of de Brito et al. (5) reported that X-tra fil was the only group among composite materials tested that did not exhibit a significant increase in roughness after biodegradation.

Although SF had the highest mean surface roughness value of all the composites tested, the image of SF specimen exhibited no significant alterations in surface patterns following either $\mathrm{pH}$-cycling or toothbrushing test (Figure 6a-c), and the values of surface roughness showed high resistance to degradation.
The SF is highly filled nanohybrid type composite resin. Due to the reduced particle dimension by nanotechnology, filler particles situated as close together may have protected the softer resin matrix of SF from abrasion (35). The GF group, another nanohybrid type composite tested, exhibited the lowest surface roughness values and smoothest optical images. These results are in agreement with some studies that reported uniformly polished surfaces after polishing, lower roughness values after toothbrushing (11) and thermocycling (4) in G-aenial Universal Flo. A new silane method used on the surface of nanoparticles to increase adhesion with the resin matrix may also be responsible for maintaining the surface properties of this material even after mechanical and chemical degradation (38). There was no statistically significant difference between GF and the microhybrid composite in the control group. Unlike roughness values, which did not show a significant increase, the optical profilometry images of GF (Figure 2c) and Z250 (Figure 3c) exhibited numerous surface irregularities after toothbrushing simulation. Similarly, Somacal et al. (23) have reported that simulated toothbrushing after the $\mathrm{pH}$ cycling caused changes in SEM images of composite surfaces, but these changes did not result in a significant increase in roughness values of most of the composite resins tested.

Filtek Bulk Fill Posterior is described by its manufacturer as a nanofilled composite containing nanoclusters and individual silica $(0.02 \mu \mathrm{m})$ and zirconia (0.004-0.011 $\mu \mathrm{m})$ nanoparticles (39). This resin group (FBF), which has a more homogeneous filler distribution with small particle size, showed significantly less surface roughness values than the other bulk-fill composites. In previous studies, smallerparticle fillers have been reported to exhibit a lower increase in surface roughness after polishing procedures (40) and brushing simulation tests $(20,28)$. It has also been stated that loosely bound nano-sized particles tend to abrade away rather than the larger nanocluster fillers being plucked from the resin matrix $(8,24,35)$. In line with this assertion, the high resistance to degradation of $\mathrm{FBF}$, shown by the roughness values and surface patterns (Figure $4 a-c$ ) obtained in the present study, may be attributed to the nano-sized inorganic filler content. A study examining the SEM images of surface texture of bulk-fill composites also reported that Filtek Bulk Fill Posterior surfaces had slight erosion, while SonicFill and X-tra fil showed deeper surface erosion following aging (4). Another study supported that with AFM and SEM images, each nano-layer or nano-cluster wore away, resulting in a similar nano-layered surface, since there are no large particles to protrude or be plucked out of the resin layer (8).

Unlike previous studies researching the surface roughness of resin composites after toothbrushing, none of the composite groups were significantly affected by the experimental periods in this study. The cleaning effect of dentifrices is mainly supported by abrasive particles (41). Brushing simulation without dentifrice was preferred herein to eliminate the abrasive effect of dentifrice on the surface properties of resin composites. Thus, the use of distilled water in this study may have caused less changes in surface roughness than other 
studies that simulate brushing with dentifrices $(7,28,42)$. As another limitation, it can be stated that the specimens were prepared in the form of a disc, but the restoration shapes and surfaces differ in clinical conditions. In further studies, it would be useful to investigate the abrasive effect of brushing with different toothpastes, considering the distance and direction of the brush to the different surfaces of the restoration.

\section{CONCLUSION}

The toothbrushing performed immediately after chemical exposure increased the surface roughness of most composite materials, even though not statistically significant. Although nanohybrid bulk-fill showed the highest roughness value, it was the most stable group with nanofilled bulk-fill after $\mathrm{pH}$ cycling and toothbrushing simulations.

\section{REFERENCES}

[1] Yap AU, Low JS, Ong LF. Effect of food simulating liquids on surface characteristics of composite and polyacid-modified composite restoratives. Oper Dent 2000; 25: 170-176.

[2] Kim RJ, Kim YJ, Choi NS, Lee IB. Polymerization shrinkage, modulus, and shrinkage stress related to tooth-restoration interfacial debonding in bulk-fill composites. J Dent 2015; 43: 430-439.

[3] Ilie N, Bucuta S, Draenert M. Bulk-fill resin based composites: an in vitro assessment of their mechanical performance. Oper Dent 2013; 38: 618-625.

[4] Karadaş M, Demirbuğa S. Evaluation of color stability and surface roughness of bulk-fill resin composites and nanocomposites. Meandros Med Dent J 2017; 18: 199-206.

[5] de Brito O, de Oliveira I, Monteiro G. Hydrolytic and biological degradation of bulk-fill and self-adhering resin composites. Oper Dent 2019; 44: E223-233.

[6] Sahadi BO, Price RB, André CB, Sebold M, Bermejo GN, PalmaDibb RG, Faraoni JJ, Soares CJ, Giannini M. Multiple-peak and single-peak dental curing lights comparison on the wear resistance of bulk-fill composites. BOR 2018; 32: e122.

[7] Al-Qahtani K, Al Bounni RS, Omari MA, Assery M. Wear and surface roughness of three different composite resins after simulated toothbrushing: an in vitro study. Int J Oral Care Res 2017; 5: 137-142.

[8] O'Neill C, Kreplak L, Rueggeberg FA, Labrie D, Shimokawa CAK, Price RB. Effect of tooth brushing on gloss retention and surface roughness of five bulk-fill resin composites. J Esthet Restor Dent 2018; 30: 59-69.

[9] Anusavice KJ, Shen C, Rawls HR. Phillips' science of dental materials. 12th Ed., St. Louis, MO: Elsevier/Saunders 2013.p.275-306.

[10] GC Corporation. G-aenial Universal Flo brochure - (cited 2019 Jan 8). Available from: http://www.gcamerica.com/products/ operatory/G-aenialFlowable/GCA_G-aenial_Bro-iPad.pdf.

[11] Lai G, Zhao L, Wang J, Kunzelmann KH. Surface properties and color stability of dental flowable composites influenced by simulated toothbrushing. Dent Mater J 2018; 37: 717-724.

[12] Lazaridou D, Belli R, Petschelt A, Lohbauer, U. Are resin composites suitable replacements for amalgam? A study of two-body wear. Clin Oral Investig 2015; 19: 1485-1492.
[13] Ferracane JL, Marker VA. Solvent degradation and reduced fracture toughness in aged composites. J Dent Res 1992; 71: 13-19.

[14] Yap AU, Tan SH, Wee SS, Lee CW, Lim EL, Zeng KY. Chemical degradation of composite restoratives. J Oral Rehabil 2001; 28: 1015-1021.

[15] Fúcıo SB, Carvalho FG, Sobrinho LC, Sinhoreti MA, PuppinRontani RM. The influence of 30-day-old Streptococcus mutans biofilm on the surface of esthetic restorative materials-An in vitro study. J Dent 2008; 36: 833-839.

[16] Turssi CP, Hara AT, Serra MC, Rodrigues AL. Effect of storage media upon the surface micromorphology of resin-based restorative materials. J Oral Rehabil 2002; 29: 864-871.

[17] Voltarelli FR, Santos-Daroz CB, Alves MC, Cavalcanti AN, Marchi GM. Effect of chemical degradation followed by toothbrushing on the surface roughness of restorative composites. J Appl Oral Sci 2010; 18: 585-590.

[18] Turssi CP, Hara AT, De Magalhaes CS, Serra MC, Rodrigues AL. Influence of storage regime prior to abrasion on surface topography of restorative materials. J Biomed Mater Res B Appl Biomater 2003; 65: 227-232.

[19] Silva KG, Pedrini D, Delbem AC, Cannon M. Effect of pH variations in a cycling model on the properties of restorative materials. Oper Dent 2007; 32: 328-335.

[20] Turssi CP, De Magalhaes CS, Serra MC, Rodrigues AL. Surface roughness assessment of resin-based materials during brushing preceded by $\mathrm{pH}$-cycling simulations. Oper Dent 2001; 26: 576-584.

[21] Featherstone JDB. Dental caries: a dynamic disease process. Aust Dent J 2008; 53: 286-291.

[22] Mozzaquatro LR, Rodrigues CS, Kaizer MR, Lago M, Mallmann $A$, Jacques LB. The effect of brushing and aging on the staining and smoothness of resin composites. J Esthet Restor Dent 2017; 29(2), E44-E55.

[23] Somacal DC, Manfroi FB, Monteiro MSG, Oliveira SD, Bittencourt HR, Borges GA, Spohr AM. Effect of pH cycling followed by simulated toothbrushing on the surface roughness and bacterial adhesion of bulk-fill composite resins. Oper Dent 2020; 45: 209-218.

[24] Carvalho FG, Sampaio CS, Fucio SBP, Carlo HL, Correr-Sobrinho L, Puppin-Rontani RM. Effect of chemical and mechanical degradation on surface roughness of three glass ionomers and a nanofilled resin composite. Oper Dent 2012; 37: 509-517.

[25] Jassé FF, de Campos EA, Lefever D, Di Bella E, Salomon JP, Krejci I, Ardu S. Influence of filler charge on gloss of composite materials before and after in vitro toothbrushing. J Dent 2013; 41: e41-44.

[26] Chadwick RG, McCabe JF, Walls AWG, Storer R. The effect of storage media upon the surface microhardness and abrasion resistance of three composites. Dent Mater 1990; 6: 123-128.

[27] Featherstone JDB, O'Reilly MM, Shariati M, Brugler S. Enhancement of remineralization in vitro and in vivo. In: Leach SA, editor. Factors relating to demineralization and remineralization of the teeth. Oxford: IRL; 1986.p.23-34.

[28] Da Costa J, Adams-Belusko A, Riley K, Ferracane JL. The effect of various dentifrices on surface roughness and gloss of resin composites. J Dent 2010; 38: 123-128.

[29] Wang L, Garcia FCP, De Araujo PA, Franco EB, Mondelli RFL. Wear resistance of packable resin composites after simulated toothbrushing test. J Esthet Restor Dent 2004; 16: 303-314. 
[30] Al-Shammery HAO, Bubb NL, Youngson CC, Fasbinder DJ, Wood DJ. The use of confocal microscopy to assess surface roughness of two milled CAD-CAM ceramics following two polishing techniques. Dent Mater 2007; 23: 736-741.

[31] Heintze SD, Forjanic M, Rousson V. Surface roughness and gloss of dental materials as a function of force and polishing time in vitro. Dent Mater 2006; 22: 146-165.

[32] Joniot S, Salomon JP, Dejou J, Gregoire G. Use of two surface analyzers to evaluate the surface roughness of four esthetic restorative materials after polishing. Oper Dent 2006; 31: 39-46.

[33] Jones CS, Billington RW, Pearson GJ. The in vivo perception of roughness of restorations. Br Dent J 2004; 196: 42-45.

[34] Bollen CM, Lambrechts $P$, Quirynen M. Comparison of surface roughness of oral hard materials to the threshold surface roughness for bacterial plaque retention: a review of the literature. Dent Mater 1997; 13: 258-269.

[35] Ergücü Z, Türkün LS. Surface roughness of novel resin composites polished with one-step systems. Oper Dent 2007; 32: 185-192.

[36] Yadav RD, Raisingani D, Jindal D, Mathur R. A comparative analysis of different finishing and polishing devices on nanofilled microfilled, and hybrid composite: a scanning electron microscopy and profilometric study. Int J Clin Pediatr Dent 2016; 9: 201-208.
[37] Barkmeier WW, Takamiza WA T, Erickson RL, Tsujimoto A, Latta $M$, Miyazaki M. Localized and generalized simulated wear of resin composites. Oper Dent 2015; 40: 322-335.

[38] Special report. Unique blend of properties in G-aenial Universal Flo. Compend Contin Educ Dent 2011; 32: 84-85.

[39] 3M ESPE. Filtek Bulk Fill Posterior Restorative technical product profile - (cited 2019 Jan 4). Available from: http:// multimedia.3m.com/mws/media/9766300/filtek-bulk-fillposterior-restorative-tpp-global-pages.pdf?fn=Filtek_Bulk_ Fill_Posterior_Resto.

[40] Ehrmann E, Medioni E, Brulat-Bouchard N. Finishing and polishing effects of multiblade burs on the surface texture of 5 resin composites: microhardness and roughness testing. Restor Dent Endod 2018; 44: e1.

[41] Wiegand A, Kuhn M, Sener B, Roos M, Attin T. Abrasion of eroded dentin caused by toothpaste slurries of different abrasivity and toothbrushes of different filament diameter. J Dent 2009; 37: 480-484.

[42] Da Silva EM, De Sá Rodrigues CUF, Dias DA, Da Silva S, Amaral CM, Guimarães JGA. Effect of toothbrushing-mouthrinsecycling on surface roughness and topography of nanofilled, microfilled, and microhybrid resin composites. Oper Dent 2014; 39: 521-529. 